2018

\title{
Minimizing Container Weight
}

Ibrahim Alomran

University of South Florida

Advisors:

Arcadii Grinshpan, Mathematics and Statistics

Hadi Charkhgard, Industrial \& Management Systems Engineering

Joseph Dietz, Physics

Problem Suggested By: Adel Al-Shayea

Field of Study for Problem Suggester: King Saud University, Industrial Engineering

Follow this and additional works at: https://digitalcommons.usf.edu/ujmm

Part of the Mathematics Commons

UJMM is an open access journal, free to authors and readers, and relies on your support: Donate Now

\section{Recommended Citation}

Alomran, Ibrahim (2018) "Minimizing Container Weight," Undergraduate Journal of Mathematical Modeling: One + Two: Vol. 9: Iss. 1, Article 6.

DOI: https://doi.org/10.5038/2326-3652.9.1.4899

Available at: https://digitalcommons.usf.edu/ujmm/vol9/iss1/6 


\title{
Minimizing Container Weight
}

\begin{abstract}
Increased globalization has resulted in increased competition in the shipping industry. Since large carriers control over $70 \%$ of the total shipping industry, small carriers are left with only $30 \%$ of the market share to compete for. Ultimately, profit margins for small carriers have become very minimal. There is, therefore, need to develop a strategy that will aid in optimizing the profits of carriers. The goal of this paper is to develop a model that will help determine the minimum weight for a particular container design. The validity of the model is important in the sense that minimum container weight will optimize the amount of cargo carried by containers thereby increasing company profits. In developing the model, the dimensions of the container are considered. The solution to the model gives the critical values of the dimensions that will yield the minimum weight for container design. Precisely, the study employs the concept of differentiation in determining the critical values for an optimized design. The model, therefore, proves to be a useful tool for container design for a particular ship.
\end{abstract}

\section{Keywords}

shipping, cargo, optimization, container design, profit

\section{Creative Commons License}

(c)

This work is licensed under a Creative Commons Attribution-Noncommercial-Share Alike 4.0 License. 


\section{Problem Statement}

The amount of cargo carried by a ship is limited by the maximum weight that the ship can carry for a particular voyage. On the other hand, the maximum cargo carried by the ship determines the transportation costs and consequently the profit obtained from transporting the cargo. The weight of the container contributes to the weight of the total container load and consequently the amount of cargo carried by the ship. It is desirable to maximize the amount of cargo carried by the ship. This can be achieved by optimizing the amount of cargo that each container can carry. One way of optimizing the amount of cargo carried by each container is by minimizing the weight of the container.

\section{Motivation}

Industrial engineering is primarily concerned with the optimization of processes and systems. Optimization of processes and systems has been made possible through the development of mathematical models that mostly use calculus tools. The solutions to the models give the critical values for the optimization of the processes and systems (Zavvar Sabegh et al., 2016). Through optimizing processes and systems, businesses have been able to reduce costs, improve quality and maximize delivery speed thereby increasing the value of their goods.

While a lot of research has been done in improving the value of goods, much has only been done in reducing production times, improving the speed of delivery and minimizing the cost of products (Kang, Medina \& Ouyang, 2008). However, little has been done in maximizing the amount of goods that can be delivered to the target customers. Precisely, the effect of maximum transported load on transport cost has not been fully investigated. However, in 
shipping of cargo, the maximum weight limit of the ship has a significant effect on the amount of cargo that a particular ship can carry and consequently the transport cost.

Research on optimization has majorly emphasized on production problems. Hall and Eillon (1963) developed optimization models that were based on cost minimization and maximization of production rates. In another study, Chen and Lin (2002) developed a model that provided solutions to the problems of a deteriorating process with shelf life products. Khan, Jaber, and Ahmad developed a mathematical model for determining the optimal inventory policy for both vendor and buyer by considering the quality of inspection at the buyer's end as well as at the vendor's end (Zavvar Sabegh et al., 2016).

Today, containerized maritime shipping is more preferred compared to the class maritime transport technology. In fact, container shipping has become the main mode of international trade (Zavvar Sabegh et al., 2016). There is a tremendous growth in the maritime fleet industry as a result of such factors as globalization, population increase, changes in standards of living and the limitation of local resources. Container ship owners therefore need to size their fleet in order for them to meet the increased demand for their services.

Malcom Mclean, an entrepreneur, was the first person to introduce the idea of containers in the shipping industry. Mclean developed the first container in 1956 (Kang, Medina \& Ouyang, 2008). Unfortunately, Mclean had no maritime experience, and his design was mostly focused on convenient loading and shipping of cargo in the ships. His idea was to build a container that would transport a larger amount of goods than before and in a more efficient and faster way while at the same time minimizing costs. Before Mclean introduced the container in the shipping industry, longshoremen used to load ships in an item by item basis (Kang, Medina \& Ouyang, 2008). Thus, by developing the container, Mclean revolutionized the shipping industry. Together 
with other investors, Mclean invested heavily in building an infrastructure for his newly developed technology. In recent years, the capacity of pure containerships has risen tremendously. Additionally, ships have continued to increase in size thus making the use of containers in transporting goods around the world easier and cheaper.

Cargo can either be in form of containerized shipping or bulk shipping (Silva \& Guedes Soares, 2014). Bulk shipping mainly involves the transport of bulk quantities such as grains, oil and ore. Normally, bulk goods require specialized vessels or bulk carriers. Containerized shipping is mostly used for transporting small cargo. On regular services, it is common to find that containers do not fill the ship to the maximum. Container shipping is mostly used in liner shipping (Hsu \& Hsieh, 2007). It is, however, important to understand that ships can operate in other shipping modes such as industrial shipping and tramp shipping. Containers can also be transported in tramp mode of shipping.

\section{International Trade and the Shipping Industry}

Many countries are removing trading barriers. The elimination of trade barriers has resulted to an increase in international trade which has consequently created an increased need for container shipping (Silva \& Guedes Soares, 2014). Despite the increased demand for container shipping industry, the shipping industry has remained a monopoly. Precisely, an excess of $70 \%$ of the total container shipping in the world is controlled by a few leading container carriers leaving on $30 \%$ of the market share under the control of the many small carriers (Silva \& Guedes Soares, 2014). Therefore, small carriers face stiff competition in an effort to increase their market share. The intense competition made it necessary for carriers to develop effective planning in their strategies and operations. On the other hand, the shipping industry is associated with an increase in operational complexities. Consequently, there is an increased need to control 
and manage the associated operational and variable costs while at the same time maintaining customer satisfaction at the highest level. With increased competition, it is apparent that profit margins have reduced thus adversely affecting the total profitability of carriers. To overcome the challenge of low revenue, models have been developed to optimize ship planning (Hsu \& Hsieh, 2007). There is also a huge chunk of literature on mathematical models that maximize shipping profits through providing solutions on improved schedules and routes as well as selecting the best combination of containers.

With the increased growth in the short sea shipping industry, there is an increasing need to develop a methodology of optimizing the transport of goods (Hsu \& Hsieh, 2007). In an effort to achieve maximum exploitation of container transport in ships, designers must consider rates of container flow on the specified sailing routes, and most importantly determine the average TEU mass in the ship design. These parameters largely depend on the characteristics of the ship technical, technological, constructional, exploitation. The technological parameters are crucial in determining the efficiency of ship operation as regards to the profit that results from the amount of cargo that can be carried in the containers for any particular voyage (Silva \& Guedes Soares, 2014). For instance, the shipping company will not make any profit if the containers of a particular ship are so arranged in a manner that empty containers are transported as a result of poor arrangement of the cargo. Models have therefore been developed to ensure that arrangement of cargo in containers is such that costs are minimized and profits maximized. However, the profit realized by the ship largely depends on the useful load of the ship and the transport capacity of the container ship. Kos and Zenzerovic used linear programming to develop a model for the optimal cargo transport structure by full container ship on predefined sailing routes (Hassan, 2012). The solution of this model provided the optimal cargo structure that could be 
transported in container ships. Basically, models based on linear programming and integer programming are the mostly used optimization models in the maritime transport industry (Kang, Medina \& Ouyang, 2008).

So far, much of the literature available focuses on the costs in maritime shipping. There is also some considerable literature on models that deal with minimizing shipping costs by computing the optimal shipping cycle time as well as the size of the fleet. In the literature, container arrivals have mostly been modeled as stochastic. We believe that the weight of the container material has a very significant impact on the total weight of the container load, consequently affecting the amount of load carried by a ship. This, in turn, affects the cost of transporting the goods and hence the profit margins. While frequent and reliable services are desired, shipping lines need to minimize the cost of carrying cargo. Achieving a minimum transport cost requires determining the minimum weight for the container material. Such a requirement necessitates the development of a model whose solutions would provide the critical values for the minimum weight of the container material.

\section{The Container Weight}

Optimization is often challenging for any complex system because complex systems are generally comprised of a variety of components and parameters with entirely different constraints (Kang, Medina \& Ouyang, 2008). Evaluation of such a system is therefore difficult, especially concerning the cost and benefit of significant changes. Considering the many constraints that determine the profitability of container shipping, careful consideration should be made to ensure that a detailed analysis is made that accounts for the contribution of all the parameters in the profitability of container shipping. Since models have already been constructed for most of the other parameters that determine ship profitability, the first motivation is to build 
an authentic model that shall represent the weight contribution of the container material to the total weight of the container load and consequently the net weight of a fully loaded ship.

Further, the weight contribution of the container material is determined by the dimensions of the container to be used. The design of different ships requires the use of containers of particular dimensions to optimize loading and minimize operational and transport costs (Kang, Medina \& Ouyang, 2008). Therefore in this case an accurate consideration of the different dimensions of the container is necessary to obtain an appropriate model that can fit the ship parameters. Thus, the model developed in this case shall include all the dimensions of the container while taking into account the dimensional constraints of the ship. Through this model, it will be possible to predict the critical values that would minimize the weight of the container to allow for maximum loading of the container ship for any particular voyage.

The container is the primary carriage unit for any particular liner ship (Kang, Medina \& Ouyang, 2008). Therefore, its maximum loading has an enormous impact on the total amount of cargo that the vessel can carry in a particular voyage. Its parameters are consequently crucial in leveraging the profitability of a specific fleet. As such, the model of the container weight can be used as one dimension of measuring the profitability of any cargo transport with a ship from one location to another. The model could also be used in predicting the safety of a particular voyage because the total weight of the ship determines the floating properties of the vessel as it moves from one port to another in a specific route. In fact, the model is fundamental in studying the floating behavior of the ship during a voyage.

Moreover, the increased competition is an indication that profits earned by carriers will increasingly become razor thin (Silva \& Guedes Soares, 2014). This trend is expected to grow considering the increased dominance of large carriers in the shipping industry. Small-scale 
carriers will, therefore, more than ever, be expected to maximize their carriage for them to reduce costs and maximize profits. However, since optimized scheduling of routes and ship planning has already been put in place, minimizing the weight of the container material can be a lucrative way of maximizing ship carriage and reducing transportation costs. Further, the model developed in this paper could serve as an essential step towards developing an integrated model for maximizing the profitability of carriers. This model will represent a potent tool that will be used to quantitatively compute the critical dimensions of any container design, which can further be used in the integrated model to evaluate the profitability of the carriers.

\section{The Ultimate Goal}

In summary, the ultimate goal of this paper is to propose an accurate model of the dimensions of containers that are to be used in a particular ship. The model will then be used to predict the minimum weight of the container that will allow for maximum cargo carriage in a specific vessel. Though a discussion of assumptions in model development will be presented later, it is worthwhile to note at this early stage that standard containers will be used in the model building, so that the critical dimensions will be the length, width and height of the container. The volume will be assumed to be fixed in this case due to the general assumption that the size is informed by other constraints of the ship.

\section{Mathematical Description and Solution Approach}

\section{Problem Definition}

The profit earned from the transport of cargo in containerized shipping is related to the amount of structure and amount of cargo loaded in the containers that are transported from one 
port to the other. Ship management is not concerned with the maximum amount of cargo that can be loaded into the container and carried. The administration is only involved with the planning of transport schedules, stowing and unloading of the containers. However, it is essential to determine the optimal amount of cargo that each container should carry to maximize profits. The amount of cargo carried by ship is limited by the maximum weight that the vessel can carry for a particular voyage. On the other hand, the maximum load carried by the vessel determines the transportation costs and consequently the profit obtained from transporting the cargo. The weight of the container contributes to the weight of the total container load and therefore the amount of cargo carried by ship. It is desirable to maximize the amount of cargo carried by ship. This can be achieved by optimizing the amount of cargo that each container can carry. One way of maximizing the amount of cargo carried by each container is by minimizing the weight of the container.

The problem of defining the minimum weight of the container occurs when it is required for the designer to select the adequate dimensions of the containers for a fixed volume of the container to maximize cargo loading. The best solution to the problem is to use differentiation. In this case, the weight of the container is differentiated with respect to a selected dimension of the container. The method of differentiation is chosen because it will quickly give the critical value of the selected size, from which the other dimensions can be computed for the minimum weight of the container. The values obtained will provide maximum container loading and hence yield the maximum profit for every voyage.

\section{Formulation of the Mathematical Model}

In solving the problem defined above, the adequate mathematical model is set as follows. 
The container is assumed to be rectangular in this model development. It is important to note that this assumption is directly derived from the fact that all standard containers are rectangular in shape. The volume of the container is assumed to be fixed throughout the development of this model:

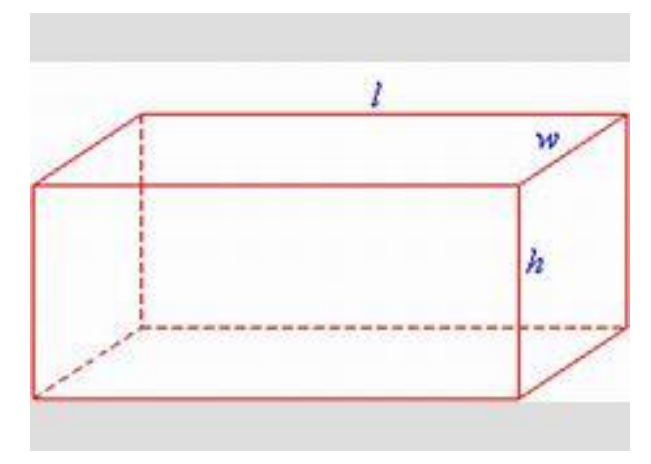

width of the container $=w$ meters,

length of the container $=l$ meters,

height of the container $=h$ meters,

mass per unit area of the material used for top and bottom $=x \frac{\mathrm{kg}}{\mathrm{m}^{2}}$,

mass per unit area of the material used for sides $=n \mathrm{~kg} / \mathrm{m}^{2}$,

volume of the container (fixed) $=V \mathrm{~m}^{3}$.

The mass $M$ of the container is thus calculated in $\mathrm{kg}$ :

$$
M=x(2 l w)+n(2 w h+2 l h) .
$$

$$
\text { Let } \quad l=a w
$$

then formulas (1) and (2) imply that:

$$
M=2\left[a x w^{2}+n w h(1+a)\right] .
$$

The volume $V$ of the container is given by

$$
V=\text { length } \times \text { width } \times \text { height }=l \times w \times h=a w \times w \times h=a w^{2} h .
$$

Hence 


$$
h=\frac{V}{a w^{2}} .
$$

Substituting equation (4) in (3) we have

$$
M=2\left[x a w^{2}+n V\left(a^{-1}+1\right) w^{-1}\right] .
$$

To solve for the minimum weight of the container according to the set calculus model means computing the critical value(s) of $w$ and then finding the corresponding values of $l$ and $h$. It is important to note that the values of $w, l$ and $h$ must be positive numbers. It is also paramount to note that the container can be made of a uniform material. Therefore, proper substitutions should be made in order to obtain the accurate solutions to the model. The problem of finding the minimum weight of the container is solved by using the method of differentiation. Due to the simplicity of the model, manual calculations can be used for the computation of the critical value(s). Thus, taking the derivative of equation (5):

$$
\frac{d M}{d w}=2\left[2 x a w-n V\left(a^{-1}+1\right) w^{-2}\right]
$$

the critical value(s) of $w$ are obtained by setting $\frac{d M}{d w}=0$. Hence $2 x a w=n V\left(a^{-1}+1\right) w^{-2}$ and

$$
w=\sqrt[3]{\frac{n V\left(a^{-2}+a^{-1}\right)}{2 x}} .
$$

Equation (6) gives the critical value of $w$ and hence the solutions to the mathematical model.

\section{Numerical Example}

To illustrate the developed calculus model, an example using real data is necessary.

An industrial engineer desires to construct a container for shipping cargo. The container has a base length that is four times the width of the base. The material used for constructing the top and bottom is estimated to weigh $20 \mathrm{~kg} / \mathrm{m}^{2}$ while the material for building the sides is estimated to weigh $3 \mathrm{~kg} / \mathrm{m}^{2}$. The container must have a volume of $500 \mathrm{~m}^{3}$. The task is to compute the dimensions of the container that will minimize the weight of the container. 


\section{Solution}

Since the representative model for the given problem is written in (5) as

$$
\begin{gathered}
M=2\left[x a w^{2}+n V\left(a^{-1}+1\right) w^{-1}\right], \text { we have: } M=2\left[20 \times 4 \times w^{2}+3 \times 500\left(\frac{1}{4}+1\right) w^{-1}\right] \text { and } \\
M=160 w^{2}+3750 w^{-1} \\
\frac{d M}{d w}=320 w-\frac{3750}{w^{2}}=0 \\
w=\sqrt[3]{\frac{375}{32}} \approx 2.271 \mathrm{~m} .
\end{gathered}
$$

Alternatively, substituting the given values to the solution in equation (6) we obtain:

$$
w=\sqrt[3]{\frac{n V\left(a^{-2}+a^{-1}\right)}{2 x}}=\sqrt[3]{\frac{3 \times 500\left(\frac{1}{16}+\frac{1}{4}\right)}{2 \times 20}} \approx 2.271 \mathrm{~m} .
$$

From equation (4) and (8), $h=\frac{V}{a w^{2}}=\frac{500}{4} \times\left(\frac{375}{32}\right)^{-2 / 3}=20 \sqrt[3]{\frac{16}{9}} \approx 24.228 \mathrm{~m}$.

From equation (2) and (8), $l=a w=4 \times \sqrt[3]{\frac{375}{32}}=10 \sqrt[3]{\frac{3}{4}} \approx 9.086 \mathrm{~m}$.

Thus, the dimensions that yield a minimum container weight include a base width of $2.271 \mathrm{~m}$, a base length of $9.086 \mathrm{~m}$ and a height of $24.228 \mathrm{~m}$ for the particular type of material used. From (7) and (8), the minimum weight $M \approx 2476 \mathrm{~kg}$.

\section{Discussion}

From the solution of the numerical example, it is apparent that the model has dramatically simplified the calculations for obtaining the critical values for the minimum container weight. In the first case, the essential values are calculated from the first principles. In the second case, the given values are directly substituted in the model solution. In both cases, the same values of 
container dimensions are obtained. Apparently, the model developed in this paper is accurate. Since the critical values can directly be obtained from the model solution equation, then it is crystal clear that the model presents a simple method of obtaining container dimensions for the minimum weight of the container material.

\section{Conclusions and Recommendations}

To realize the value of containerized shipping, it is always essential to optimize the transport of the cargo. Optimizing the transport of cargo means to either maximize the profits earned or minimize the expenses incurred in the transportation of cargo. Since the success of container shipping largely depends on the profits obtained, it is necessary to develop a model that would yield a significant profit margin for the transport of cargo. Among the many ways of maximizing profit it is ensuring that containers carry the optimal amount of cargo. One method of optimizing the container cargo is by minimizing the weight of the empty container. The model presented in this paper is very essential in determining the critical dimensions for the design of containers for a particular ship. In this model, a calculus approach is proposed because the minimum weight can be computed by differentiating the container weight function. The model is valid considering the reduced profit margins that small carriers continue to earn as a result of the increasingly stiff competition in the shipping industry. While this model provides an essential way of maximizing shipping profits, it is important to realize that many factors determine shipping profits. Therefore, to ensure accurate optimization of shipping profits, it is recommended that an integrated model should be developed that accounts for the contribution of all the possible variables. Considering the validity of the mathematical model developed in this paper, it is essential that the integrated model includes the general solution as part of given solution. 


\section{Nomenclature}

\begin{tabular}{ccc}
\hline Symbol & Description & Value \\
\hline$w$ & width of the container & $\approx 2.271 \mathrm{~m}$ \\
$I$ & length of the container & $\approx 9.086 \mathrm{~m}$ \\
$\mathrm{~h}$ & height of the container & $\approx 24.228 \mathrm{~m}$ \\
$M$ & mass of the container & $\approx 2476 \mathrm{~kg}$ \\
$T E U$ & twenty-foot equivalent unit & - \\
\hline
\end{tabular}

\section{References}

Chen, J. M., \& Lin, C. S. (2002). An optimal replenishment model for inventory items with normally distributed deterioration. Production Planning \& Control, 13, 470-480.

Hall, R. I., \& Eillon, S. (1963). Controlling production processes which are subject to linear trend. Operational Research Quarterly, 14, 179-189.

Hassan, K. (2012). Effect of Container Stack Arrangements on the Power Optimization of a Container Ship. Journal Of Ship Production And Design, 28(1). http://dx.doi.org/10.5957/jspd.28.1.110014

Hsu, C., \& Hsieh, Y. (2007). Routing, ship size, and sailing frequency decision-making for a maritime hub-and-spoke container network. Mathematical And Computer Modelling, 45(7-8), 899-916. http://dx.doi.org/10.1016/j.mcm.2006.08.012 
Kang, S., Medina, J., \& Ouyang, Y. (2008). Optimal operations of transportation fleet for unloading activities at container ports. Transportation Research Part B: Methodological, 42(10), 970-984. http://dx.doi.org/10.1016/j.trb.2008.02.003

Silva, C., \& Guedes Soares, C. (2014). Sizing a fleet of containerships for a given market. PROMET-Traffic\&Transportation, 26(4).

http://dx.doi.org/10.7307/ptt.v26i4.1387

Zavvar Sabegh, M., Mirzazadeh, A., Maass, E., Ozturkoglu, Y., Mohammadi, M., \& Moslemi, S. (2016). A mathematical model and optimization of total production cost and quality for a deteriorating production process. Cogent $\quad$ Mathematics, 3(1). http://dx.doi.org/10.1080/23311835.2016.1264175 